\title{
Structural analysis and design of irregular shaped reinforced concrete slabs using a simplified design method
}

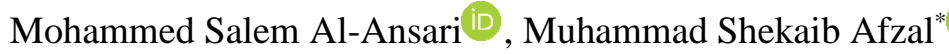 \\ Qatar University, Department of Civil and Architectural Engineering, Doha, Qatar
}

\begin{abstract}
This paper presents a simplified method to analyze and design the irregular reinforced concrete slabs based on structural safety and economy. The triangular, trapezoidal, and curved slab sections are selected in this study to be analyzed and designed using a simplified design method approach (SDM) as these sections are the most common type of irregular slab sections used in the construction industry. Flexural design formulas for triangular and curved slabs are derived based on the theoretical principles of plate and yield line theories and ACI building code of design constraints. Numerical examples are presented in this study to illustrate the method capability of designing the most commonly used irregular slabs sections. The complete design of four triangular slabs (TS-1 to TS-4) and four curved slabs (CS-1 to CS-4) is provided in this study. Besides, the required equivalent (triangular and rectangular) shaped sections are provided to deal with irregular trapezoidal slab section. The selected irregular slab sections (triangular and curved slab sections) are also analyzed and designed using the computer software (SAFE) and the results obtained are compared with the numerical solutions. The percentage difference of the simplified method with the finite element software (SAFE) ranges from $4 \%$ to $12 \%$. The results obtained for all the selected irregular shaped slab sections indicates that the SDM is a good and quick approach to design irregular (triangular and curved) slab sections.
\end{abstract}

\section{Keywords}

Irregular slab sections; Triangular slabs; Trapezoidal slabs; Curved slab sections; Simplified design method Received: 11 June 2020; Accepted: 16 September 2020

ISSN: 2630-5763 (online) C 2020 Golden Light Publishing All rights reserved.

\section{Introduction}

Reinforced concrete slabs are the most important structural component in the construction industry and the most common practice to design any reinforced concrete slab is to start with the selection of slab type (one-way slabs, two-way slabs, waffle slabs, flat slabs, or pre-cast or pre-stressed slabs) [1]. The most common type of slabs used in the construction industry is the flat slab. A flat slab is also easy for the contractor to construct in a shorterduration. Moreover, out of other slab sections, the rectangular slab section is the most common slab section used in the construction industry and it is the first choice for the designers to design the slabs as the rectangular slab section. In any case, there are scenarios, where the irregular slab sections do exists, such as trapezoidal slab section, triangular slab section, circular/curved slab section; hexagonal shaped section, etc. depends on the client's choice. The designer in this case has to stick with the client's preference and has to analyze and design the required irregular slab section. The most common irregular shaped sections are triangular, trapezoidal, and circular/shaped sections. Fig.1

\footnotetext{
* Corresponding author

Email: shekaib@qu.edu.qa
} 
shows the regular and irregular slab pattern (slabs S-1 to S-17) consisting of rectangular, triangular, trapezoidal, hexagonal, and curved shaped slab sections. The dashed lines in Fig.1 represents the beams running across the slab. In this paper, the design moments to calculate the required area of steel (As) are presented using the simplified design approach for triangular and curved shaped slabs. These design moments can be used directly by the designer to design such type of irregular slabs to fulfill the client's requirement. Safety and reliability were used in the flexural design of reinforced concrete slabs of different sections using the ultimate-strength design method USD under the provisions of ACI building code of design (ACI 318-14) [2]. Here, the curved shaped slabs are the type of circular slabs, as sometimes, the projected length of the circular slab is not equal to the radius of the circle (S-14 and S-17 in Fig.1). Therefore, the term, curved slab will be used in this present research work.

Most of the previous studies only talk about the design of flat slabs for irregular column layout. Baskaran, K. [3] in his research study introduced the structural membrane approach to design the flat slab on an irregular column grid. Further, he also performed some experimental results to validate his theoretical approach. Hillerborg, Arne [4] in his book introduced the strip method of design for the design of slabs having Irregular plan or that carry unevenly distributed loads. Bao, Tong Yuesheng Qian Guo Fang Wu [5] performed experimental research on irregular concrete slabs and validate the results with the theoretical approach of using the strip design method. The other similar research studies can be found elsewhere [6-8]. These previous research studies did not specify any quick and simple design approach to analyze and design for irregular slab sections particularly triangular and curved shaped slab sections. In this study, a quick and simplified design approach is provided to design these irregularly shaped slab sections. Since, it's a simplified design method, which will ease the design of these types of irregular slabs quite efficiently.

The triangular, trapezoidal, and curved slab sections are selected in this study to be analyzed and designed using a simplified design method approach (SDM). The slab design using the SDM method is made per the provisions of the ACI building design code (ACI -318-14) and meets the requirements of the regulation.

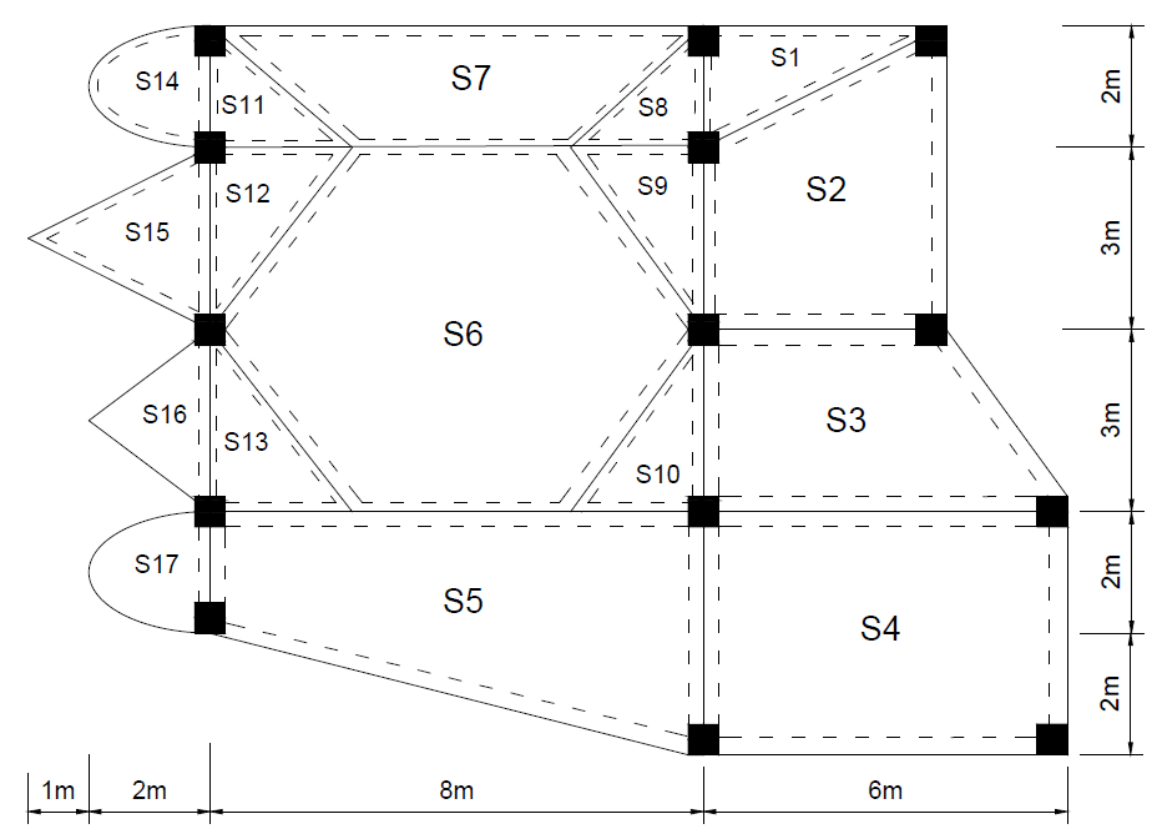

Fig. 1. Irregular slab pattern 
The design of irregular reinforced concrete slabs is based on structural safety and economy. Flexural design formulas for triangular and curved slabs are derived based on the theoretical principles of plate and yield line theories [11-12], the formula proposed by Timoshenko [13-14], and ACI building code of design constraints provided in other concrete books [15-16]. Slabs reinforcement is provided near the tension face of the slab. Slab sizes are mostly governed by the ultimate external bending moment $\left(M_{U}\right)$, and the optimized section of reinforced concrete slabs could be achieved by least allowable slab depth $(\mathrm{H})$ and reinforcing steel area $\left(A_{s}\right)$ according to ACI code of design (ACI 318-16).

Numerical examples are presented in this study to illustrate the method capability of designing the most commonly used irregular slabs sections. The complete design of four triangular slabs and four curved slabs (each having two slabs with beams and two as cantilever slabs) is provided in this study. Besides, it describes dealing with the trapezoidalshaped slab sections. Mathcad software [17] is used in this research work to formulate this simplified design approach. The selected slab sections (triangular and curved slab sections) are also analyzed and designed using the computer software (SAFE) and the results obtained are compared with the SDM numerical solutions.

\section{Flexural design moment equations}

The design procedure of irregular slabs is formulated to achieve the best slab dimension that will give the safest and economical section to resist the external bending moment $\left(M_{U}\right)$ for a specified value of the design moment strength $\left(M_{C}\right)$ based on the desired level of safety (ACI 318-14).

The slab margin of safety is given by:

$M=M_{C}-M_{U}$

where;

$M c$ = Design Moment Strength

$M_{U}=$ External ultimate bending moment

$M=$ Margin of safety

The reinforcement area $(A s)$ of the slab can be formulated using the following equation;
$A s=\frac{M u}{\varphi_{b} f y\left(d-\frac{a}{2}\right)}$

where;

$\varphi_{b}=$ Bending reduction factor

$f y=$ Specified yield strength of non-prestressed reinforcing

As $=$ Area of tension steel

$d=$ Effective depth

$a=$ Depth of the compression block

Also,

$d_{S}^{L} \leq d \leq d_{S}^{U}$

$A s_{S}^{M i n i} \leq A s \leq A s_{S}^{M a x}$

$A s^{\operatorname{Max}}=0.75 \times \beta 1 \times \frac{f^{\prime} c}{f y}\left(\frac{600}{600+f y}\right) b d$

$A s^{M i n i}=\left(\frac{1.4}{f y}\right) b d$

Moreover,

$\beta 1=0.85$ for $f^{\prime} \mathrm{C} \leq 30 \mathrm{MPa}$

$\beta 1=0.85-0.008\left(f^{\prime} c-30\right) \geq 0.65$

for $f^{\prime} \mathrm{C}>30 \mathrm{MPa}$

where $d_{B}^{L}$ and $d_{B}^{L}$ are slab depth, lower and upper bounds, and $A s_{B}^{\text {Mini }}$ and $A s_{B}^{\text {Max }}$ are slab steel reinforcement area, lower and upper bounds.

\section{Irregular slab sections}

Triangular and curved shaped slab sections as described in Fig. 1 are selected to be analyzed and designed in this study using the ultimate-strength design method (USD) under the provisions of ACI building code of design. The design results of these irregular slab sections are also compared with the computer software (SAFE) results. Table 1 illustrates the slab specification matrix. TS-1 and TS-2 are the triangular slab sections with beams whereas, TS-3 and TS-4 are the cantilever slab sections. Similarly, CS-1 and CS-2 are the curved slabs with beam, while CS-3 and CS-4 are the cantilever curved slab sections. The concrete compressive strength $\left(f_{c}^{\prime}\right)$ and the steel yield strength $\left(f_{y}\right)$ for these irregular slabs are $30 \mathrm{MPa}$ and $400 \mathrm{MPa}$ respectively. Moreover, the beams running across the slabs are having a cross-section of $(250 \mathrm{~mm} \times 400 \mathrm{~mm})$ with the $\left(f_{c}^{\prime}\right)=30 \mathrm{MPa}$ and $\left(f_{y}\right)=400 \mathrm{MPa}$. 
Table 1. Slab specification matrix

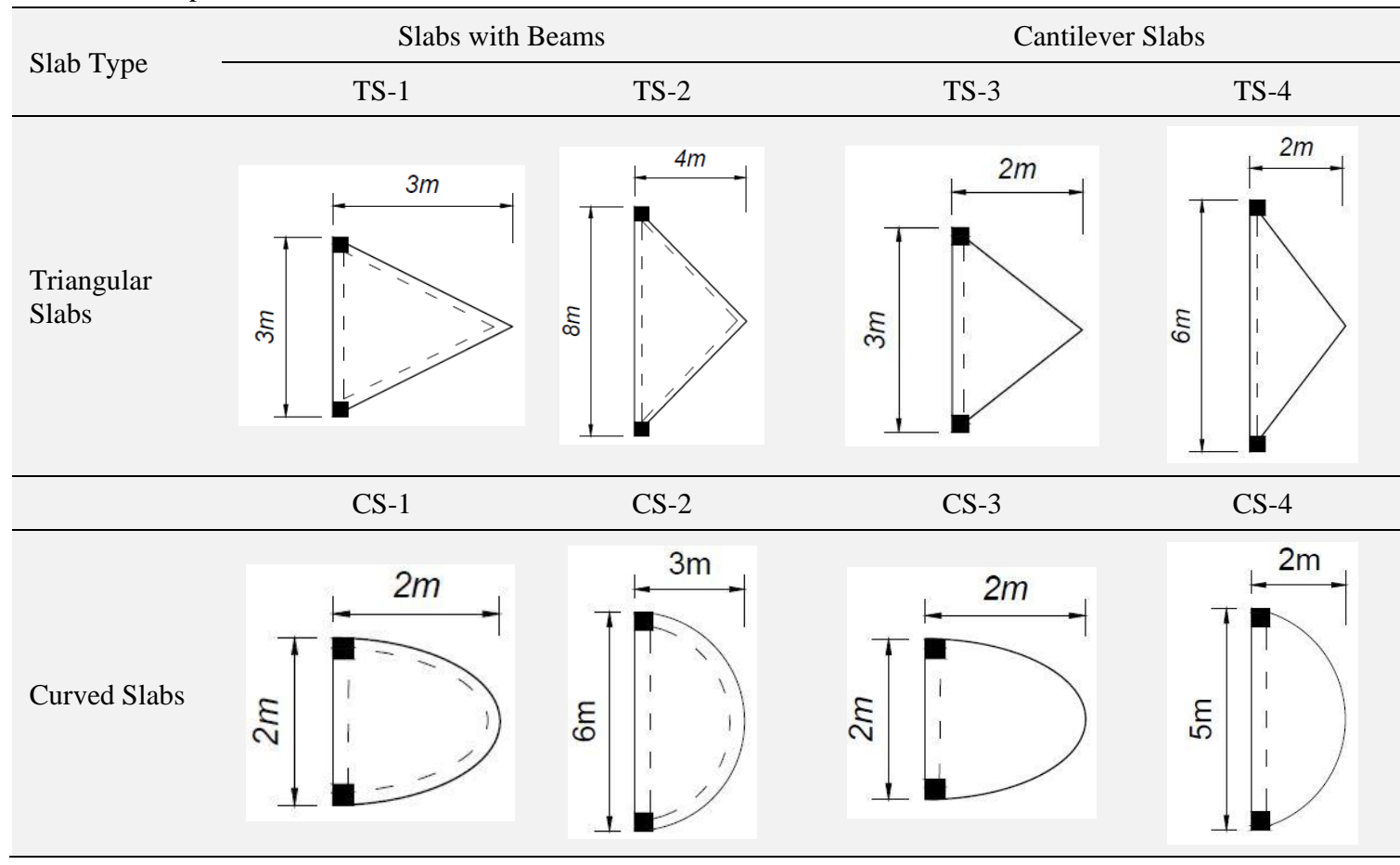

The following design steps need to be executed to determine the slab flexural strength $(M c)$ and the required steel area $(A s)$.

Step-1: Minimum slab thickness $H_{S T A R T}$ (ACI

318-14 code for minimum thickness)

Step-2: Ultimate load calculation

$$
W_{U}=\text { D.L.F }\left(w_{S D L}\right)+\operatorname{L.L.F}\left(w_{S L L}\right)
$$

Step-3: Ultimate Positive Moment $M_{U}^{+}$

Step-4: Steel area for positive moment $A_{S}^{+}$

Step-5: Nominal slab strength Check

$$
\emptyset M_{N}^{+}=M_{C}^{+}>M_{U}^{+}
$$

Step-6: Ultimate Negative Moment $M_{U}^{-}$

Step- 7: Steel area for negative moment $A_{S}^{-}$

Step-8: Nominal slab strength Check

$$
\varnothing M_{N}^{-}=M_{C}^{-}>M_{U}^{-}
$$

Step-9: Slab reinforcement detailing

\subsection{Moment equations for irregular slabs}

The moment equations for the triangular and curved slabs with and without beams (cantilever) are mentioned in this section. These moment equations, as illustrated in Table 2, can be used directly for any of these shaped slab sections to find the required positive and negative moments $\left(M_{U}^{+}, M_{U}^{-}\right)$ respectively. The moment equations provided in Table 2 are taken from the yield line theory method provided by Hsueh [11] and Hognestad [12]. The formulas related to the yield line theory method for slabs are also provided in several concrete design books [14-15]. Moreover, Timoshenko [13] proposed the second formula for the triangular slabs mentioned in Table 2.

For a triangular slab, one needs to take the larger of the two moments obtained from the two different methods (the yield line theory method and the formula proposed by Timoshenko) and design the slab against the larger moment under the provision of ACI building code of design. However, for the curved slabs, the provided moment equations are only from the yield line theory-method and that moment will be taken for the slab design accordingly.

\subsection{Trapezoidal slab}

A trapezoidal slab is the most common irregular slab type used in the construction industry. It can be either converted to a triangular or rectangular slab based on the conditions mentioned in Table 3 . 
Table 2. Irregular slab moment equations

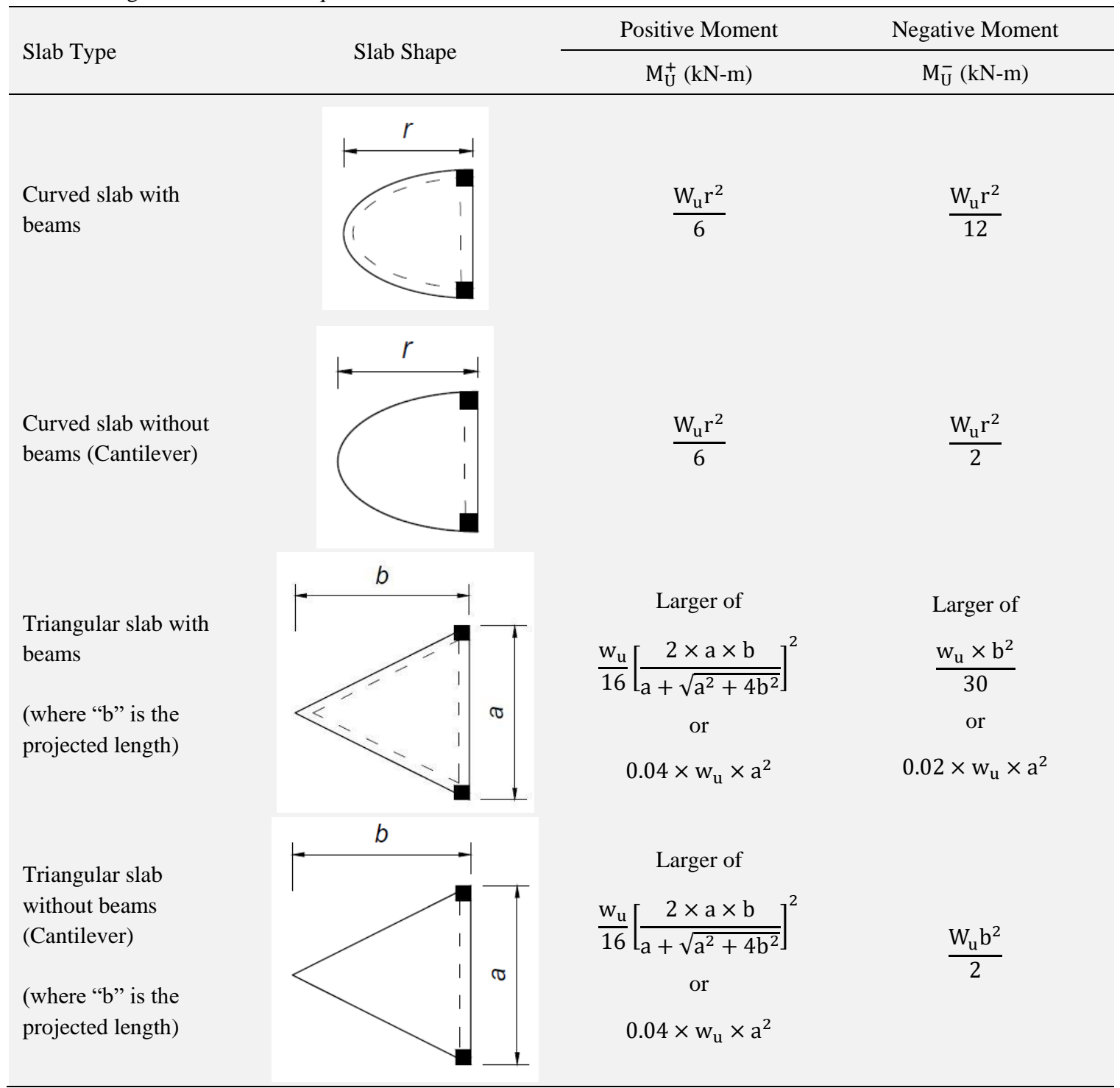

Table 3. Equivalent trapezoidal slab sections

\begin{tabular}{|c|c|c|c|}
\hline Trapezoidal Slab & Condition(s) & Equivalent triangular slab & Equivalent rectangular slab \\
\hline a & $\begin{array}{l}\text { 1) If } \mathrm{a}^{\prime} \leq \frac{\mathrm{a}}{5} \\
\text { (Triangular Slab) } \\
\text { 2) If } \mathrm{a}^{\prime}>\frac{\mathrm{a}}{5} \\
\text { (Rectangular Slab) }\end{array}$ & $+\quad a$ & $\mid \begin{array}{ll}\mid & \begin{array}{ll}1 \\
1\end{array} \\
-\frac{1}{2}\left(a+a^{\prime}\right) \rightarrow\end{array}$ \\
\hline
\end{tabular}


The equivalent triangular shape slab can be solved using the same moment equations mentioned in Table 2. Whereas, if the trapezoidal slab is converted to its equivalent rectangular shape, it can be analyzed and designed using the traditional rectangular two-way slab design using the coefficient method.

\section{Slab design loads}

Table 4 defines the input load values that applied to the selected irregular slab sections (triangular and curved shaped slabs).

The common design parameters used for these irregular slabs are as follows; $f_{y}=400 \mathrm{MPa}$

$f_{c}^{\prime}=30 \mathrm{MPa}$

$\gamma_{c}=25 \mathrm{kN} / \mathrm{m}^{3}$

$d_{b}=12 \mathrm{~mm}$

$d^{\prime}=30 \mathrm{~mm}$

where,

$d_{b}=$ diameter of the rebar

$d^{\prime}=$ cover to top reinforcement

\subsection{Design examples of triangular slabs}

This section describes the analysis and design of triangular slabs using the simplified design method (SDM). Table 5 contains the detailed results of the triangular slab with beams whereas Table 6 illustrates the design results for the cantilever triangular slabs.

Table 4. Slab design load parameters

\begin{tabular}{cccccc}
\hline Slab no. & Slab code & Dead load $(\mathrm{kN} / \mathrm{m} 2)$ & Live load $(\mathrm{kN} / \mathrm{m} 2)$ & D.L.F & L.L.F \\
\hline 1 & TS-1 & 15 & 8 & 1.2 & 1.6 \\
2 & TS-2 & 5 & 3 & 1.4 & 1.7 \\
3 & TS-3 & 10 & 8 & 1.2 & 1.6 \\
4 & TS-4 & 15 & 10 & 1.4 & 1.7 \\
5 & CS-1 & 10 & 6 & 1.4 & 1.7 \\
6 & CS-2 & 15 & 10 & 1.2 & 1.6 \\
7 & CS-3 & 10 & 8 & 1.2 & 1.6 \\
8 & CS-4 & 15 & 10 & 1.2 & 1.6 \\
\hline
\end{tabular}

Table 5. Design examples of triangular slabs with beams

\begin{tabular}{|c|c|c|}
\hline Item & TS-1 (Slab with beams) & TS-2 (Slab with beams) \\
\hline Slab Plan & m & $\underset{\infty}{ }$ \\
\hline $\mathrm{H}(\mathrm{mm})$ & 130 & 170 \\
\hline $\mathrm{W}_{\mathrm{U}}(\mathrm{kN} / \mathrm{m})$ & 37.9 & 18.05 \\
\hline $\mathrm{M}_{\mathrm{U}}^{+}(\mathrm{kN}-\mathrm{m} / \mathrm{m})$ & $\begin{array}{l}\text { Larger of ( } 8.143 \text { and } 13.644) \\
13.64 \text { (controls) }\end{array}$ & $\begin{array}{l}\text { Larger of (12.388 and 46.208) } \\
46.208 \text { (controls) }\end{array}$ \\
\hline $\mathrm{A}_{\mathrm{S}}^{+}\left(\mathrm{mm}^{2} / \mathrm{m}\right)$ & $\begin{array}{l}409.88 \\
(\varnothing 12 @ 300 \mathrm{~mm})\end{array}$ & $\begin{array}{l}1017.8 \\
(\emptyset 12 @ 125 \text { mm })\end{array}$ \\
\hline $\mathrm{M}_{\mathrm{C}}^{+}(\mathrm{kN}-\mathrm{m} / \mathrm{m})$ & $16.965>13.64$ & $48.376>47.208$ \\
\hline $\mathrm{M}_{\mathrm{U}}^{-}(\mathrm{kN}-\mathrm{m} / \mathrm{m})$ & $\begin{array}{l}\text { Larger of (11.37 and 6.822) } \\
11.37 \text { (controls) }\end{array}$ & $\begin{array}{l}\text { Larger of ( } 9.627 \text { and } 23.104) \\
23.104 \text { controls }\end{array}$ \\
\hline $\mathrm{A}_{\mathrm{S}}^{-}\left(\mathrm{mm}^{2} / \mathrm{m}\right)$ & $\begin{array}{l}409.88 \\
(\varnothing 12 @ 300 \mathrm{~mm})\end{array}$ & $\begin{array}{l}564.5 \\
(\emptyset 12 @ 250 \mathrm{~mm})\end{array}$ \\
\hline $\mathrm{M}_{\mathrm{C}}^{-}(\mathrm{kN}-\mathrm{m} / \mathrm{m})$ & $16.965>11.37$ & $27.6>23.104$ \\
\hline
\end{tabular}


Table 6. Design examples of cantilever triangular slabs

\begin{tabular}{|c|c|c|}
\hline Item & TS-3 (Cantilever Slab) & TS-4 (Cantilever Slab) \\
\hline Slab Plan & 1 & E) \\
\hline $\mathrm{H}(\mathrm{mm})$ & 200 & 200 \\
\hline $\mathrm{W}_{\mathrm{U}}(\mathrm{kN} / \mathrm{m})$ & 30.8 & 45 \\
\hline $\mathrm{M}_{\mathrm{U}}^{+}(\mathrm{kN}-\mathrm{m} / \mathrm{m})$ & $\begin{array}{l}\text { Larger of (4.33 and 11.09) } \\
11.09 \text { (controls) }\end{array}$ & $\begin{array}{l}\text { Larger of (9.282 and 64.8) } \\
64.8 \text { (controls) }\end{array}$ \\
\hline $\mathrm{A}_{\mathrm{S}}^{+}\left(\mathrm{mm}^{2} / \mathrm{m}\right)$ & $\begin{array}{l}678.6 \\
(\varnothing 12 @ 200 \mathrm{~mm})\end{array}$ & $\begin{array}{l}1131 \\
(\varnothing 12 @ 110 \mathrm{~mm})\end{array}$ \\
\hline $\mathrm{M}_{\mathrm{C}}^{+}(\mathrm{kN}-\mathrm{m} / \mathrm{m})$ & $40.229>11.088$ & $69.403>64.8$ \\
\hline $\mathrm{M}_{\mathrm{U}}^{-}(\mathrm{kN}-\mathrm{m} / \mathrm{m})$ & 61.6 & 90 \\
\hline $\mathrm{A}_{\mathrm{S}}^{-}\left(\mathrm{mm}^{2} / \mathrm{m}\right)$ & $\begin{array}{l}1131 \\
(\varnothing 12 @ 110 \mathrm{~mm})\end{array}$ & $\begin{array}{l}1696 \\
(\varnothing 12 @ 65 \text { mm })\end{array}$ \\
\hline $\mathrm{M}_{\mathrm{C}}^{-}(\mathrm{kN}-\mathrm{m} / \mathrm{m})$ & $66.167>61.6$ & $94.26>90$ \\
\hline
\end{tabular}

\subsection{Design examples of curved slabs}

This section contains the analysis and design of curved slabs using the simplified design method (SDM). Table 7 contains the detailed results of the curved slab with beams whereas Table 8 illustrates the design results for cantilever-curved slabs.

\section{Results and discussions}

These irregular triangular and curved shaped slab sections are also analyzed and designed by the computer software (SAFE). The results obtained from the computer software are depicted in Tables 9 to 12 .

\subsection{Triangular slabs}

This section displays the required area of steel (As) results obtained for the triangular slab section using the simplified design method as well as from the SAFE software. Table 9 shows the comparison of the results obtained for triangular slabs. Slabs TS-1 and TS-2 are triangular slabs with beams whereas slabs TS-3 and TS-4 are the cantilever triangular slabs. Moreover, a comparison table of the moments obtained using the SDM method approach and the safe software are also provided in Table 10.

The results obtained from the safe software showed a good agreement with the required area of steel using the simplified design method. The bar charts in Fig. 2 also compares the results for the required area of steel $\left(A_{S}^{+}\right.$and $\left.A_{S}^{-}\right)$for theoretical $(S D M)$ and software (SAFE) approaches. The triangular slab with beams (TS-1 and TS-2), where the positive moment dominates, has the required area of steel slightly higher using the computer software compared to SDM approach with a percentage difference of $6 \%$ to $8 \%$. For the cantilever slab sections (TS-3 and TS-4), where the negative moment dominates, the required area of steel obtained from the computer software and using the SDM method approach gives almost similar results with a percentage difference of $4 \%$ to $8 \%$. In addition, the deflection contours obtained from the SAFE software are shown in Fig. 3. 
Table 7. Design examples of curved slabs with beams

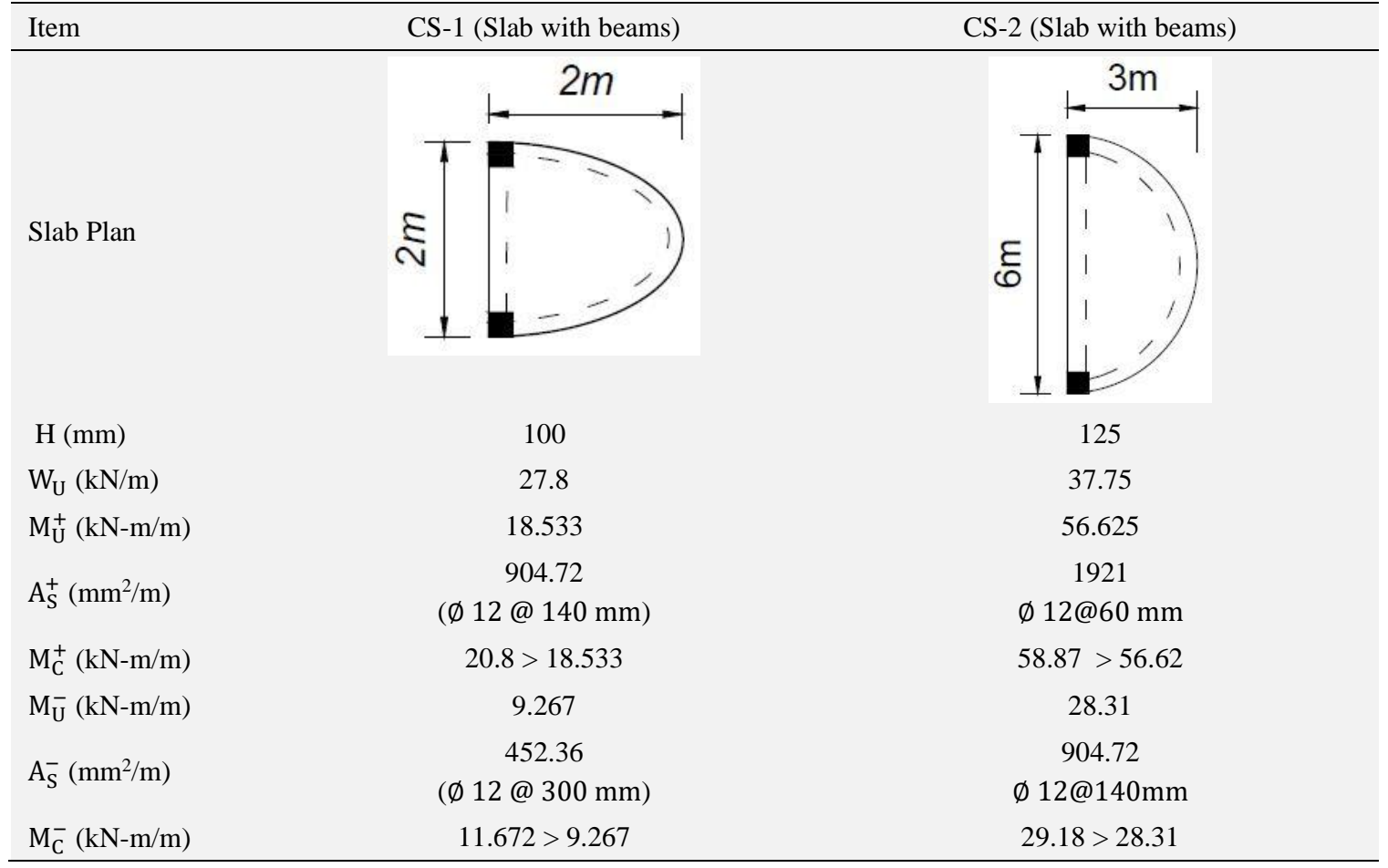

Table 8. Design examples of cantilever curved slabs

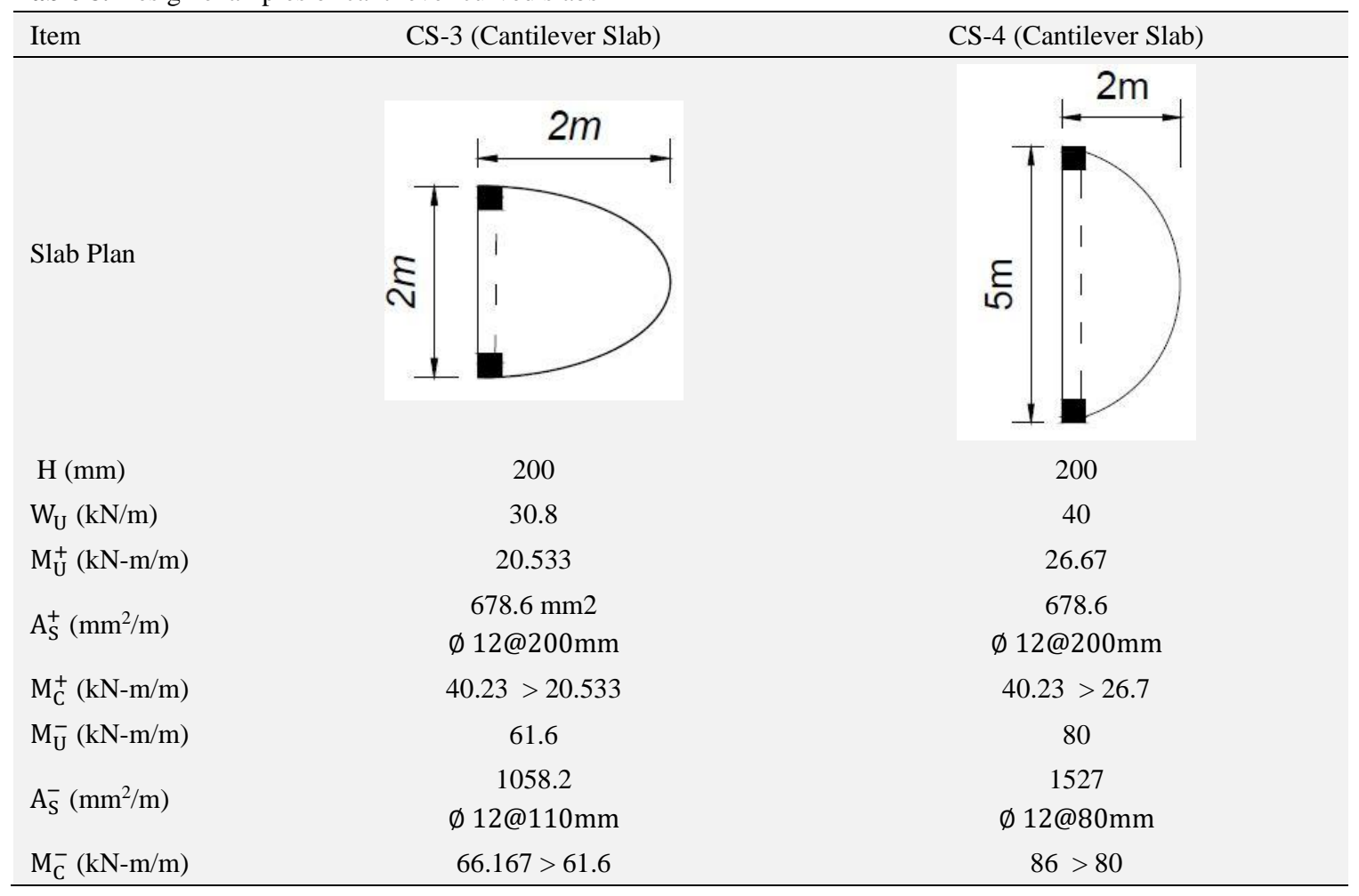


Table 9. Triangular slab results

\begin{tabular}{lccccccc}
\hline & \multicolumn{2}{c}{ SDM Method } & & \multicolumn{3}{c}{ SAFE software } \\
\cline { 2 - 3 } \cline { 7 - 8 } Slab Type & $\begin{array}{c}\text { Thickness }(\mathrm{h}) \\
(\mathrm{mm})\end{array}$ & $\mathrm{A}_{\mathrm{S}}^{+}\left(\mathrm{mm}^{2} / \mathrm{m}\right)$ & $\mathrm{A}_{\mathrm{S}}^{-}\left(\mathrm{mm}^{2} / \mathrm{m}\right)$ & & $\mathrm{A}_{\mathrm{S}}^{+}\left(\mathrm{mm}^{2} / \mathrm{m}\right)$ & $\mathrm{A}_{\mathrm{S}}^{-}\left(\mathrm{mm}^{2} / \mathrm{m}\right)$ & $\begin{array}{c}\text { Deflection } \\
(\mathrm{mm})\end{array}$ \\
\hline TS-1 & 130 & 409.88 & 409.88 & & 446 & 446 & 1.12 \\
TS-2 & 170 & 1178.8 & 564.5 & & 1265 & 632 & 5.6 \\
TS-3 & 200 & 678.6 & 1131 & & 519 & 1031 & 5.7 \\
TS-4 & 200 & 1131 & 1696 & & 1083 & 1682 & 10.76 \\
\hline
\end{tabular}

Table 10. Triangular slab results

\begin{tabular}{lccccc}
\hline \multirow{2}{*}{ Slab Type } & \multicolumn{2}{c}{ SDM Method } & & \multicolumn{2}{c}{ SAFE Software } \\
\cline { 2 - 3 } \cline { 5 - 6 } & $\mathrm{M}^{+\mathrm{ve}}(\mathrm{kN}-\mathrm{m} / \mathrm{m})$ & $\mathrm{M}^{-\mathrm{ve}}(\mathrm{kN}-\mathrm{m} / \mathrm{m})$ & & $\mathrm{M}^{+\mathrm{ve}}(\mathrm{kN}-\mathrm{m} / \mathrm{m})$ & $\mathrm{M}^{-\mathrm{ve}}(\mathrm{kN}-\mathrm{m} / \mathrm{m})$ \\
\hline \multirow{2}{*}{$\mathrm{TS}-1$} & 13.64 & 11.37 & & $11.66($ Minimum & Reinforcement) \\
TS-2 & 46.208 & 23.104 & & 4.8 (Minimum \\
TS-3 & 11.09 & 61.6 & & 48.35 & Reinforcement) \\
TS-4 & 64.8 & 90 & & 9.8 & 25.69 \\
\hline
\end{tabular}

Table 11. Curved slab results

\begin{tabular}{lccccccc}
\hline & \multicolumn{3}{c}{ SDM Method } & & \multicolumn{3}{c}{ SAFE Software } \\
\cline { 2 - 3 } \cline { 7 - 8 } Slab Type & $\begin{array}{c}\text { Thickness }(\mathrm{h}) \\
(\mathrm{mm})\end{array}$ & $\mathrm{A}_{\mathrm{S}}^{+}\left(\mathrm{mm}^{2} / \mathrm{m}\right)$ & $\mathrm{A}_{\mathrm{S}}^{-}\left(\mathrm{mm}^{2} / \mathrm{m}\right)$ & & $\mathrm{A}_{\mathrm{S}}^{+}\left(\mathrm{mm}^{2} / \mathrm{m}\right)$ & $\mathrm{A}_{\mathrm{S}}^{-}\left(\mathrm{mm}^{2} / \mathrm{m}\right)$ & $\begin{array}{c}\text { Deflection } \\
(\mathrm{mm})\end{array}$ \\
\hline CS-1 & 100 & 904.72 & 452.36 & & 455 & 455 & 1.1 \\
$\mathrm{CS}-2$ & 125 & 1921 & 904.72 & & 1779 & 679 & 8.48 \\
$\mathrm{CS}-3$ & 200 & 678.6 & 1058.2 & & 678 & 1193 & 5.03 \\
$\mathrm{CS}-4$ & 200 & 678.6 & 1527 & & 595 & 1746 & 11.51 \\
\hline
\end{tabular}

Table 12. Curved slab moment results

\begin{tabular}{|c|c|c|c|c|}
\hline \multirow{2}{*}{ Slab Type } & \multicolumn{2}{|c|}{ SDM Method } & \multicolumn{2}{|c|}{ SAFE Software } \\
\hline & $\mathrm{M}^{+\mathrm{ve}}(\mathrm{kN}-\mathrm{m} / \mathrm{m})$ & $\mathrm{M}^{-\mathrm{ve}}(\mathrm{kN}-\mathrm{m} / \mathrm{m})$ & $\mathrm{M}^{+\mathrm{ve}}(\mathrm{kN}-\mathrm{m} / \mathrm{m})$ & $\mathrm{M}^{-\mathrm{ve}}(\mathrm{kN}-\mathrm{m} / \mathrm{m})$ \\
\hline CS-1 & 18.533 & 9.267 & 12.8 & $\begin{array}{l}4.8 \text { (Minimum } \\
\text { Reinforcement) }\end{array}$ \\
\hline CS-2 & 56.625 & 28.31 & 54.52 & $\begin{array}{l}15.74 \text { (Minimum } \\
\text { Reinforcement) }\end{array}$ \\
\hline CS-3 & 20.53 & 61.6 & $\begin{array}{l}10.8 \text { (Minimum } \\
\text { Reinforcement) }\end{array}$ & 71.03 \\
\hline CS-4 & 26.67 & 90 & 22.07 & 97.23 \\
\hline
\end{tabular}


Table 13. Deflection results for triangular and curved slabs

\begin{tabular}{lcc}
\hline \multirow{2}{*}{ Slab Type } & \multicolumn{2}{c}{ Deflection $(\mathrm{mm})$} \\
\cline { 2 - 3 } & SAFE software & ACI Deflection Limits \\
\hline TS-1 & 1.12 & 8.33 \\
TS-2 & 5.6 & 11.1 \\
TS-3 & 5.7 & 12.5 \\
TS-4 & 10.76 & 25.0 \\
CS-1 & 1.1 & 5.56 \\
CS-2 & 8.48 & 16.67 \\
CS-3 & 5.03 & 8.33 \\
CS-4 & 11.51 & 20.83 \\
\hline
\end{tabular}
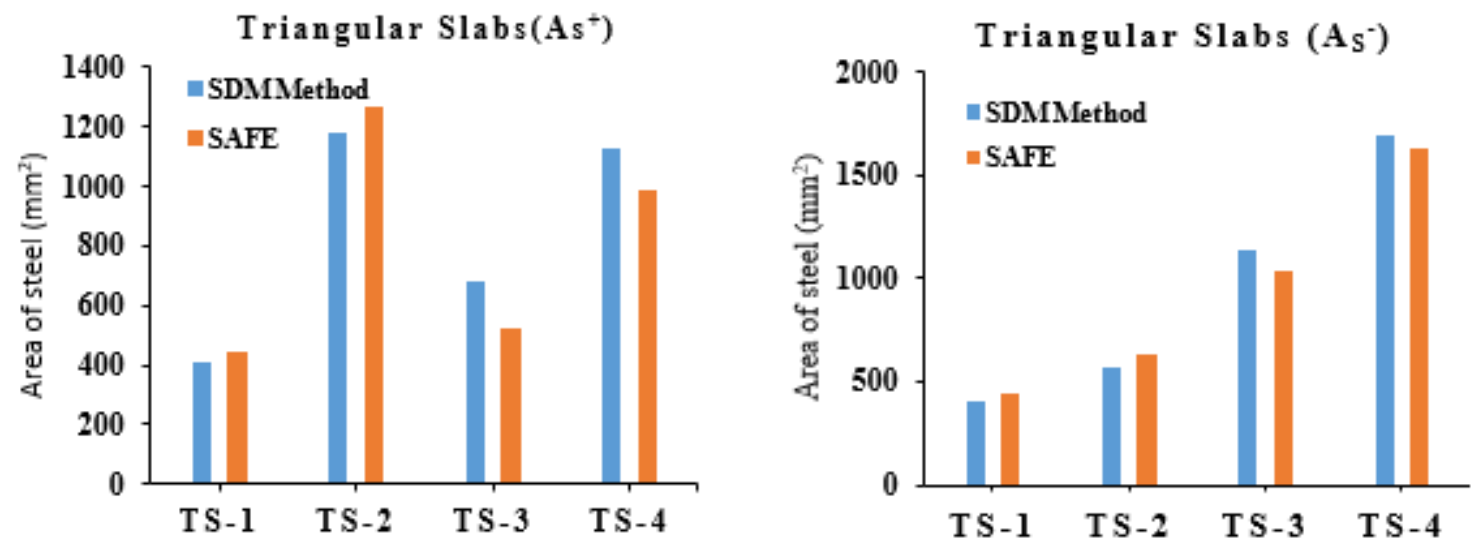

Fig. 2. Area of steel $(A s)$ comparison for triangular slabs

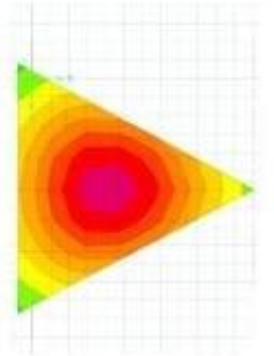

a) $T S-1$

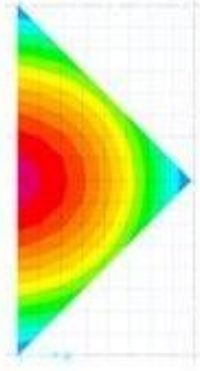

b) $T S-2$

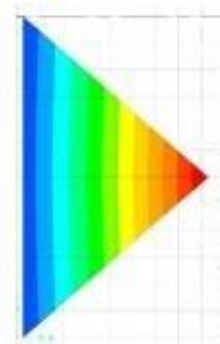

c) $T S-3$

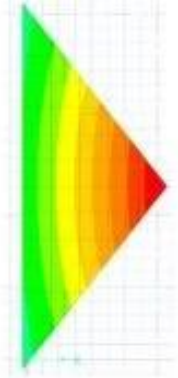

d) $T S-4$

Fig. 3. Deflection contours of triangular slabs

\subsection{Curved slabs}

The required area of steel $(A s)$ results obtained for the curved slab section using the computer software (SAFE) are compared with the SDM and are illustrated in Table 11. Moreover, a comparison table of the moments obtained using the SDM method approach and the safe software are also provided in Table 12.

The moment results in SDM method, obtained for the curved slab with beams (CS-1 and CS-2), 
where the positive moment dominates, are higher compared to the software results and thus results in a higher area of steel. On the other hand, for the cantilever curved slabs (CS-3 and CS-4), where negative moment dominates, the negative moment values obtained from the SAFE software are slightly higher than the proposed SDM method which results in a higher area of reinforcement compared to SDM method approach (Fig. 4).

The moment equations to calculate the positive and negative moments using SDM approach are only dependent on the " $r$ " value of the curved slab section. This " $r$ " is the projected length of the curved slab section. Moreover, the deflection contours obtained from the SAFE software are also shown in Fig. 5.

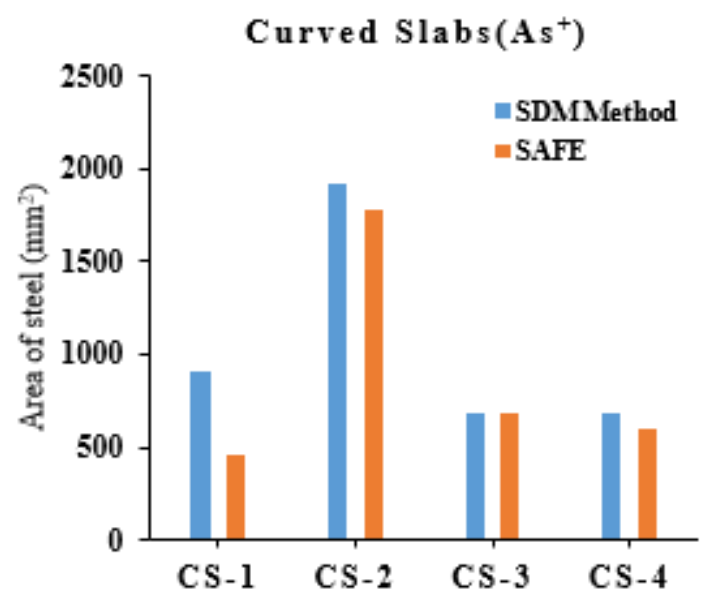

In addition, the deflection results obtained in each slab are compared with the ACI code limit (L/240) for cantilever slabs and (L/360) for slabs with beams. The comparison results are illustrated in Table 11. For cantilever slabs, (ACI 318-2011 Table 9.5-b), if the cantilever is attached to nonstructural elements that could be damaged by large deflections, the maximum allowable deflection is (span/360) under live loads and if not attached to the supporting elements, the maximum allowable deflection is (span/240) under live loads. The deflection results showed that all of the eight selected irregular slab sections have deflection values less than the allowable deflection according to the ACI code of design (ACI 318-14) indicating good and safe design.

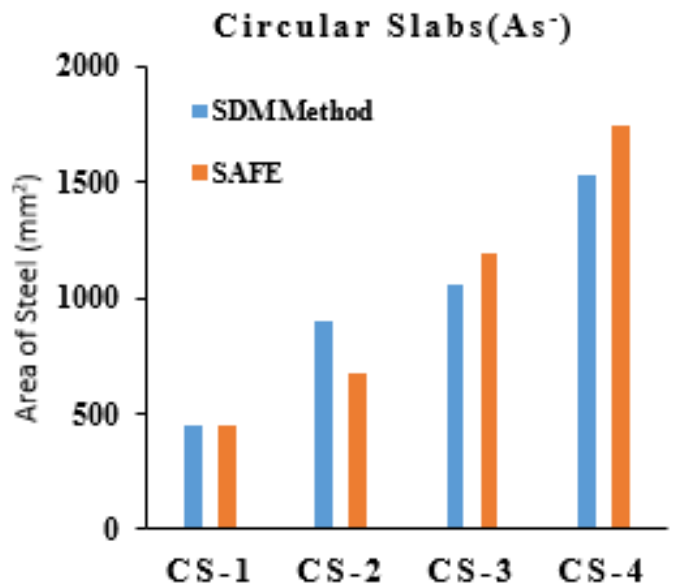

Fig. 4. Area of steel (As) comparison for curved slabs

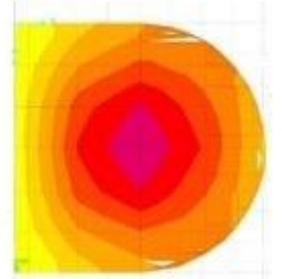

a) $C S-1$

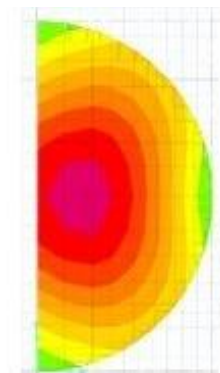

b) $C S-2$

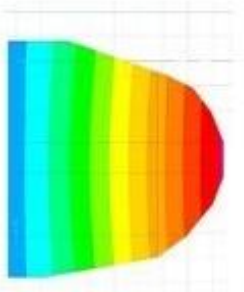

c) CS-3

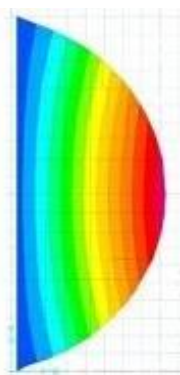

d) $\mathrm{CS}-4$

Fig. 5. Deflection contours of curved slabs 


\section{Conclusion}

This paper presents a simplified method to design irregular reinforced concrete slabs based on structural safety and economy. Triangular and curved shaped slab sections are selected as irregularly shaped slab sections to be analyzed and designed. Flexural design formulas for triangular and curved slabs are derived based on ACI building code of design (ACI 318-14).

Eight slab sections, four with beams and the remaining four as cantilever slab sections, are selected in this study to be analyzed and designed using the simplified design method. The moment equations derived using this simplified approach can be used for any irregular triangular and curved shaped slab sections. These moment equations give the positive and negative moments quite easily to determine the required area of steel (As) in that particular slab section. In addition, the irregular trapezoidal-shaped section can be either converted to an equivalent triangular slab section or it can be converted to its equivalent rectangular-shaped section with the required formulas mentioned in this study. The equivalent triangular-shaped slab can be solved using the same moment equations mentioned in Table 2. Whereas, if the trapezoidal slab is converted to its equivalent rectangular shape, it can be analyzed and designed using the traditional rectangular two-way slab design using the coefficient method.

For triangular slabs, the slab sections with beams (TS-1 and TS-2) have the required area of steel slightly higher using the computer software compared to SDM approach with a percentage difference of $6 \%$ to $8 \%$. However, for cantilever triangular slab sections(TS-3 and TS-4), the required area of steel obtained from the computer software and using the SDM method approach gives almost similar results with a percentage difference of $4 \%$ to $8 \%$. The area of steel results obtained for the curved slab with beams (CS-1 and CS-2) and cantilever curved slabs (CS-3 and CS-4) are slightly higher and are more conservative using this SDM approach compared to the software results. Besides, the deflection results obtained for all slabs (regular and cantilever) are within the acceptable deflection range compared to the allowable deflection, according to ACI code of design (ACI 318-14), indicating good and safe design.

The results obtained from all of the selected irregular-shaped slab sections indicate that the simplified design method SDM is a safe, economical, and quick approach to design irregular (triangular and curved) slabs sections.

\section{Declaration of conflicting interests}

The author(s) declared no potential conflicts of interest concerning the research, authorship, and/or publication of this article.

\section{References}

[1] Aldwaik M, Hojjat A (2016) Cost optimization of reinforced concrete flat slabs of arbitrary configuration in irregular high rise building structures. Structural and Multidisciplinary Optimization 54(1): 151-164.

[2] ACI Committee 318. Building Code Requirements for Structural Concrete (ACI 318-14): An ACI Standard: Commentary on Building Code Requirements for Structural Concrete (ACI 318R14): an ACI Report. American Concrete Institute, 2014.

[3] Baskaran K (2008) Irregular flat slabs designed according to the structural membrane approach. Magazine of Concrete Research 60(8): 587.

[4] Hillerborg A (1974) Strip Method of Design: Monograph. Transport and Road Research Laboratory (TRRL), Buckinghamshire, England.

[5] Bao TY, Qian G, Fang W (1993) Experimental research on irregular reinforced concrete slabs. China Civil Engineering Journal 26(4): 63-70.

[6] Deaton JB (2005) A Finite Element Approach to Reinforced Concrete Slab Design. Ph.D. Thesis, Georgia Institute of Technology.

[7] Haitao T, Shenjia T, Yuesheng S (2004) Limit design of reinforced concrete rectangular slab with complex boundary supports. Building Structure 34(6): 25-27.

[8] Guofang T, Yuesheng T, Shenjia Q (1997) Experimental research and limit calculation of RC L shaped slabs. Journal of Xi'an University of Architecture \& Technology (Natural Science Edition) 29(4): 368-372. 
[9] McCormac JC, Brown RH (2015) Design of Reinforced Concrete. John Wiley \& Sons.

[10] Park R, Gamble WL (1999) Reinforced Concrete Slabs. John Wiley \& Sons.

[11] Hsueh PK (1996) The Yield-line Theory for Concrete Slabs. MSc Thesis, Kansas State University, Manhattan, Kansas.

[12] Hognestad E (1953) Yield-line theory for the ultimate flexural strength of reinforced concrete slabs. Journal Proceedings 49(3): 637-656.

[13] Timoshenko SP, Woinowsky-Krieger S (1959) Theory of Plates and Shells. McGraw-Hill.
[14] Timoshenko SP, Gere JM (2009) Theory of Elastic Stability. Courier Corporation, McGraw-Hill.

[15] Siddiqi ZA (2013) Concrete Structures: Part-I. Help Civil Engineer Publisher, Lahore, Pakistan.

[16] Hassoun MN, Al-Manaseer A (2012) Structural Concrete: Theory and Design. John Wiley \& Sons.

[17] Al-Ansari MS, Senouci AB (1999) MATHCAD: Teaching and learning tool for reinforced concrete design. International Journal of Engineering Education 15(1): 64-71. 